\title{
Use of a Synaptosomal Model to Monitor Drug-Induced in vivo Changes in the $\gamma$-Aminobutyric Acid Content of Nerve Endings and its Relevance to Research on Antipsychotic Drugs
}

\author{
J.D. WOOD
}

SUMMARY: The validity of a synaptosomal model to monitor drug-induced changes in the y-aminobutyric acid (GABA) content of nerve endings is reviewed. Examples of data obtained using the model are presented and the possibility of using the model for research on antipsychotic drugs is discussed.

\begin{abstract}
RESUME: Nous étudions la validité d'un modèle synaptosomial permettant de suivre les changements induits par les drogues sur le contenu en GABA des terminaisons nerveuses. Nous présentons des exemples des résultats obtenus avec le modèle et discutons de la possibilité d'employer le modèle pour la recherche sur les médicaments antipsychotiques.
\end{abstract}

From the Department of Biochemistry, University of Saskatchewan, Saskatoon.

Reprint requests to J.D. Wood, Department of Biochemistry, University of Saskatchewan, Saskatoon, Canada S7N OW0.
Although the biochemical basis of schizophrenia remains elusive, the hypothesis that schizophrenic symptoms reflect altered dopamine activity has become established as the most prominent current theory (Berger et al., 1978). The theory does not, however, account for the effects of the butyrophenones which are among the most potent antipsychotic agents, but which are relatively weak antagonists of dopamine. It has, however, become increasingly apparent that the proper interaction and integration of different neurotransmitter pathways is vital for the normal functioning of the central nervous system, specific examples being the interaction of the dopamine system and the GABA system in brain regions such as the striatum-substantia nigra (McGeer et al., 1978) and the limbic system (Perez de la Mora and Fuxe, 1977). Thus, there is the possibility that druginduced changes in the GABA system may affect schizophrenia via the action of the GABA pathways on the dopamine system. Indeed, Fuxe et al. (1979) suggested that the combined treatment with neuroleptics and GABAergic drugs may improve the efficacy of the former. It would also provide an explanation for the antipsychotic potency of the butyrophenones if these compounds can be shown to affect both the GABA system and the dopamine system.

Data from various laboratories including my own clearly indicate that there is no simple relationship between the excitable state of the brain and changes in whole brain GABA content (Table I). This is not surprising when one considers the high degree of compartmentation of GABA in brain tissue (eg. in glia, nerve ending and neuronal perikarya respectively) and the possibility that a drug may induce different changes in the GABA content of the different compartments. A similar "masked" situation might well exist with regard to whole brain
GABA content and the antipsychotic action of drugs, if indeed the GABA system is involved at all. It therefore seems mandatory to examine the effects of the drugs on the GABA system, not only in discreet regions of the brain, but also in individual GABA compartments. In view of the critical role which nerve endings play in nerve transmission, a study of the GABA content of this subcellular compartment may provide the greatest insight into the action of drugs on the functioning of the GABA system.

Unfortunately, the current state of technology does not allow the direct measurement of drug-induced changes in the GABA content of nerve endings. On the other hand, there are wellestablished procedures for isolating synaptosomes which are derived from nerve endings, but, although GABA levels can readily be determined in these organelles, there remains the uncertainty as to whether the data thus obtained represent the true state of affairs in the nerve endings in the intact animal. Possible problems include postmortem increases in GABA during removal of the tissue and preparation of the homogenate, redistribution of GABA during tissue homogenization and subcellular fractionation procedures, leakage of GABA from synaptosomes during the isolation procedures, and metabolism of GABA in these organelles during their preparation.

Recent studies in our laboratory have shown that the GABA content of synaptosomes is more stable than previously thought, and that the above-mentioned concerns are more apparent than real. For example, the addition of GABA to the homogenizing medium does not alter the synaptosomal GABA content (Table II), thereby indicating that no redistribution of 
TABLE I

GABA Levels in Mouse Brain at the Onset of Seizures

\begin{tabular}{lccc}
\hline $\begin{array}{c}\text { Convulsant agent } \\
(\mathrm{mmol} / \mathrm{kg} \text { body wt) }\end{array}$ & $\begin{array}{c}\text { Time to onset of } \\
\text { seizures } \\
(\mathrm{min})\end{array}$ & $\begin{array}{c}\text { Whole brain } \\
(\mu \mathrm{mol} / \mathrm{g})\end{array}$ & $\begin{array}{c}\text { GABA } \\
\text { Synaptosomal } \\
(\mathrm{nmol} / \mathrm{mg} \text { protein) }\end{array}$ \\
\hline None & & $2.08 \pm 0.03(4)$ & $31.6 \pm 1.6(6)$ \\
Hydrazine (4.0) & $28.5 \pm 1.7(12)$ & $2.46 \pm 0.09^{*}(4)$ & $22.2 \pm 1.8^{*}(6)$ \\
INH (2.2) & $29.4 \pm 1.9(12)$ & $1.71 \pm 0.06^{*}(4)$ & $23.6 \pm 1.5^{*}(6)$ \\
AOAA (3.6) & $7.6 \pm 0.3(12)$ & $2.03 \pm 0.07(4)$ & $22.3 \pm 0.1^{*}(6)$ \\
\hline
\end{tabular}

Values are the mean \pm S.E.M. for the number of samples given in brackets.

- Significantly different from controls, $\mathrm{P}<0.01$.

Data from Wood, et al., (1979).

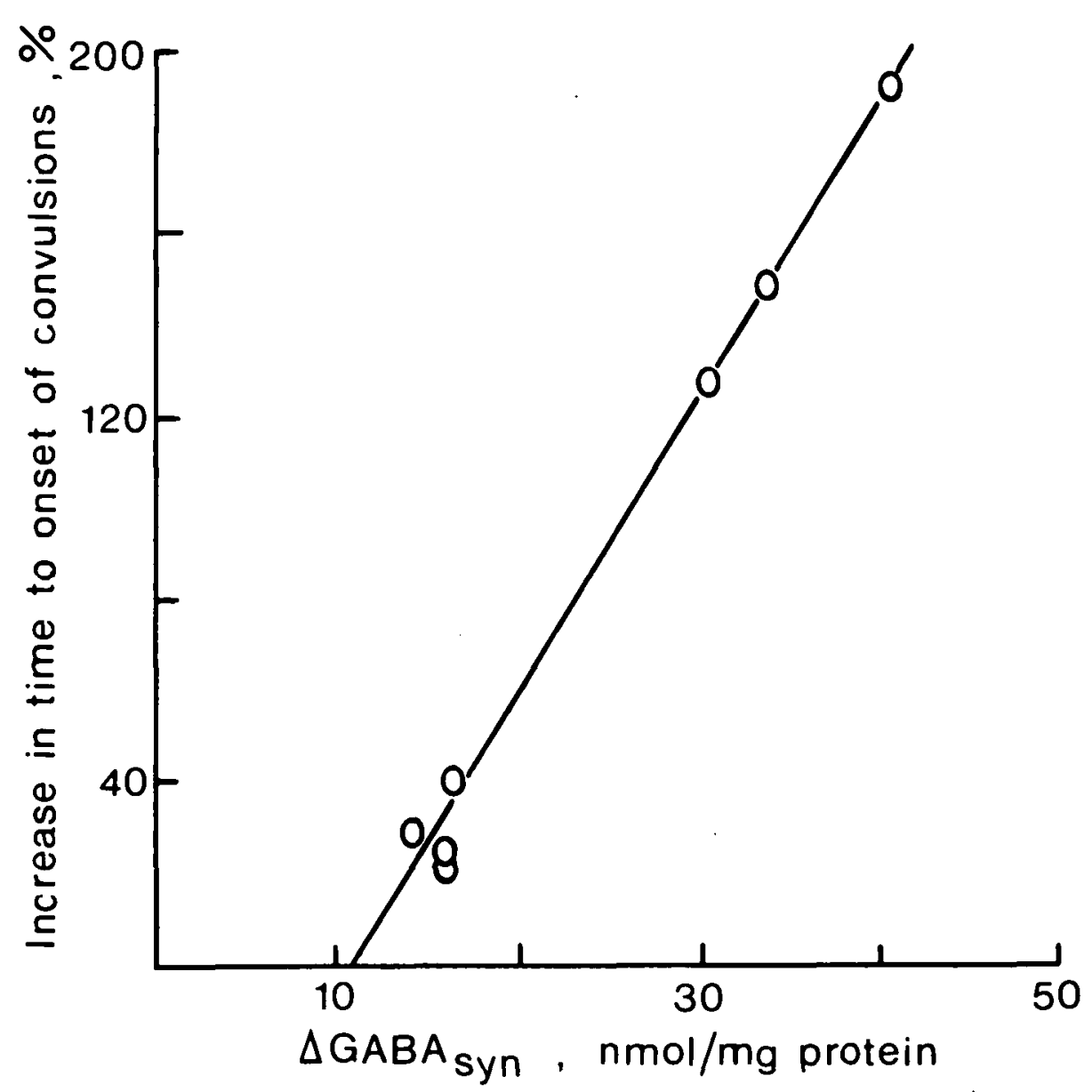

Figure I - Relationship between elevation in GABA content of synaptosomal-enriched fractions and delay in onset of seizures. Data were obtained using various dosage levels of aminooxyacetic acid and L-cycloserine as anticonvulsant agents and of isonicotinic acid hydrazide, unsymmetrical dimenthylhydrazine and aminooxyacetic acid as convulsant agents. $\triangle \mathrm{GABA}_{\text {syn }}$ indicates the increase in GABA level due to anticonvulsant drug pretreatment at the time of injection of the convulsant agent. See Wood, et al. (1980) for further details.
GABA is occurring. Moreover, the GABA content of synaptosomes fractioned by the standard centrifugation procedure is the same as that of synaptosomes which are subjected to the same procedure for a second time (Table II), thereby indicating that leakage of GABA from synaptosomalenriched fractions during their isolation is negligible. A detailed account of the evidence used to establish synaptosomal-enriched fractions as a viable model for evaluating drug-induced changes in nerve endings may be found in papers by Wood et al. (1978 and 1979). Although data arising from use of the model cannot provide an absolute measure of the GABA content of nerve endings, since only a portion of the isolated synaptosome will arise from GABA-ergic terminals, changes in synaptosomal GABA content may be expected to parallel changes in the GABA levels in the terminals.

When the synaptosomal model is used to monitor the effects of convulsant agents on the GABA system, it is found that, unlike the situation with whole brain GABA levels, an excellent correlation is obtained between decreases in synaptosomal (nerve ending) GABA content and the onset of seizures (Table I). In addition, an excellent correlation is obtained between the anticonvulsant action of GABAelevating agents and the increase in synaptosomal GABA content brought about by the drugs (Fig. 1).

It is suggested that the synaptosomal model should now be used to evaluate whether any antipsychotic drugs affect the GABA system, and studies with this objective in mind are now underway in our laboratory. Any positive findings will be invaluable in elucidating more clearly the mechanisms involved in the actions of the antipsychotic agents.

\section{REFERENCES}

BERGER, P.A., ELLIOTT, G.R. and BARCHAS, J.D. (1978). Neuroregulators and schizophrenia. In Psychopharmacology: A Generation of Progress. Eds. M.A. Lipton, A. DiMascio and K.F. Killam. Publ. Raven Press, New York, 1071-1082.

FUXE, K., ANDERSSON, K., OGREN, S.-O., PEREZ DE LA MORA, M., SCHWARCZ, R., HOKFELT, T., ENEROTH, P., GUSTAFSSON, J.-A., and SKETT, P. (1979). GABA neurons and their interaction 
TABLE II

GABA Content of Synaptosomal-Enriched Fractions Prepared Under Different Experimental Conditions

\section{Conditions}

GABA

(nmol/mg protein)

Brain homogenized in $0.32 \mathrm{M}$ sucrose

$28.0 \pm 0.7$

Brain homogenized in $0.32 \mathrm{M}$ sucrose containing $1 \mathrm{mM}$ GABA

$28.0 \pm 1.2$

Synaptosomes isolated by standard Cotman procedure

$21.6 \pm 0.9$

Synaptosomes isolated by repeating the fractionation

Data from Wood, et al. (1978, 1979).

with monoamine neurons. An Anatomical, Pharmacological and functional analysis. In GABA neurotransmitters: Pharmacochemical, Biochemical and Pharmacological Aspects. Eds. P. Krogsgaard-Larsen, J. Scheel-Kruger and H. Kofod. Publ.
Munksgaard, Copenhagen, 74-94.

McGEER, P.L., ECCLES, J.C. and McGEER, E.G. (1978). Molecular Neurobiology of the Mammalian Brain. Publ. Plenum Press, New York, p. 211.
PEREZ, DE LA MORA, M. and FUXE, $K$ (1977). Brain GABA, dopamine and acetylcholine interactions. 1. Studies with oxotremovine. Brain Res. 135, 107-122.

WOOD, J.D., KURYLO, E. and NEWSTEAD, J.D. (1978). Aminooxyacetic acid induced changes in $\gamma$-aminobutyrate metabolism at the subcellular level. Can. J. Biochem. 56, 667-672.

WOOD, J.D., RUSSELL, M.P., KURYLO, E. and NEWSTEAD, J.D. (1979). Stability of synaptosomal GABA levels and their use in determining the in vivo effects of drugs: convulsant agents. J. Neurochem. 33, 61-68.

WOOD, J.D., RUSSELL, M.P. and KURYLO, E. (1980). The $\gamma$-aminobutyrate content of nerve endings (synaptosomes) in mice after the intramuscular injection of $\gamma$-aminobutyrate-elevating agents: a possible role in anticonvulsant activity. J. Neurochem. (in press). 